\title{
Noticias 2016
}

María Angélica Rozas Rozas Alvarez

Instituto de Investigaciones Museológicas y Artísticas / Universidad Ricardo Palma

mqrozas@yahoo.com

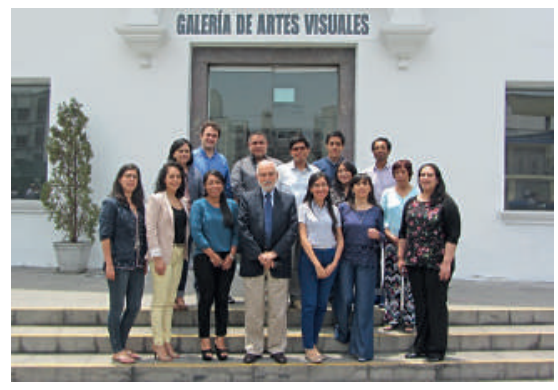

BIENVENIDA A LA PROMOCIÓN 2016-2017. En el mes de marzo de 2016 ingresaron veinte alumnos a la Maestría en Museología y Gestión Cultural, siendo la treceava desde que se fundó en el año 2000. Les deseamos mucho éxito en esta especialidad tan necesaria en nuestro medio urgido de especialistas que velen por la integridad de nuestro patrimonio y su difusión.

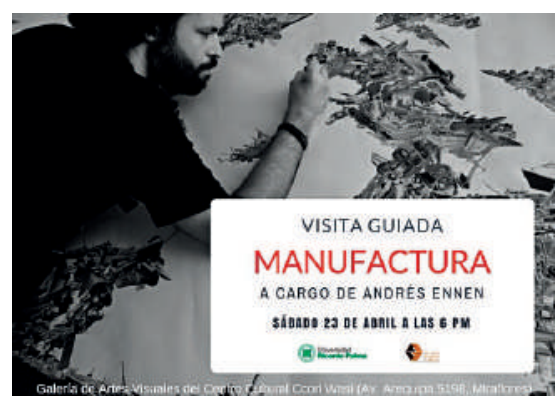

MANUFACTURA. Primera individual del artista Andrés Ennen, en la que, a través de dibujos al carbón e impresiones sobre papel, nos plantea una crítica a la sociedad de consumo, la acumulación desmedida y rápido deshecho de objetos. "La obra de arte se sitúa en un contexto de producción, circunscribiendo la labor del artista al acto mero y a la acción propia del hacer". La muestra se presentó del 7 al 30 de abril 2016 en la Galería de Artes Visuales del Centro Cultural Ccori Wasi.

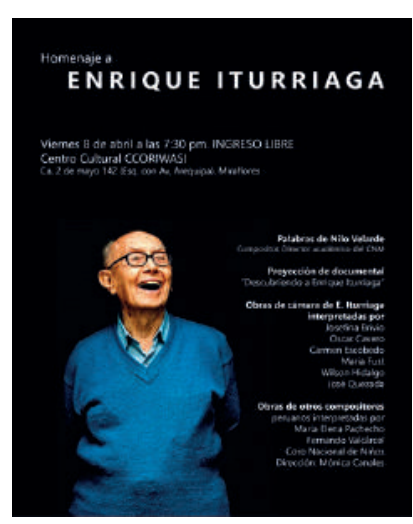

El 8 de abril, la Universidad Ricardo Palma, a través de su Instituto de Investigaciones Museológicas y Artísticas y en coordinación con el Conservatorio Nacional de Música, organizó el HOMENAJE AL MAESTRO ENRIQUE ITURRIAGA, uno de los compositores de música académica más reconocidos y de más larga trayectoria en nuestro país. Entre sus galardones se cuentan haber sido dos veces acreedor del Premio Nacional de Música "Luis Duncker Lavalle" y haber recibido la Medalla de Honor de la Cultura Peruana del Instituto Nacional de Cultura del Perú en el año 2005. 


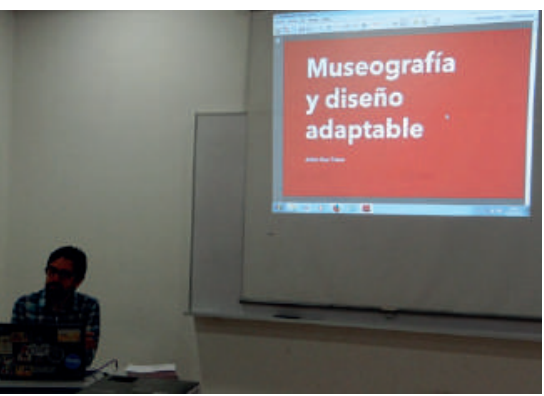

El Instituto de Investigaciones Museológicas y Artísticas, en coordinación con la Asociación de Museólogos del Perú, organizaron la conferencia "MUSEOGRAFÍA Y DISEÑO ADAPTABLE", que fue realizada el 22 de abril y estuvo a cargo del museólogo y diseñador gráfico colombiano Julián Roa, quien nos habló sobre la importancia del diseño gráfico en las exposiciones, a través de su experiencia en Colombia y así como su intervención en el Lugar de la Memoria, en Perú.

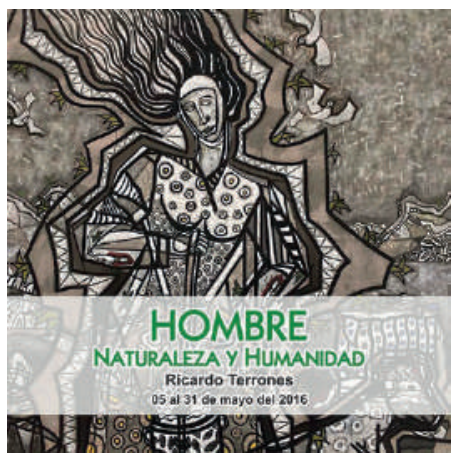

HOMBRE: NATURALEZA Y HUMANIDAD del artista trujillano Ricardo Terrones fue una exposición de pinturas en la que el artista indaga, a través de sus dibujos y simbologías, cómo el ser humano se integra y relaciona con la naturaleza. La muestra tuvo lugar del 5 al 31 de mayo en las instalaciones de la Galería de Artes Visuales del Centro Cultural Ccori Wasi.

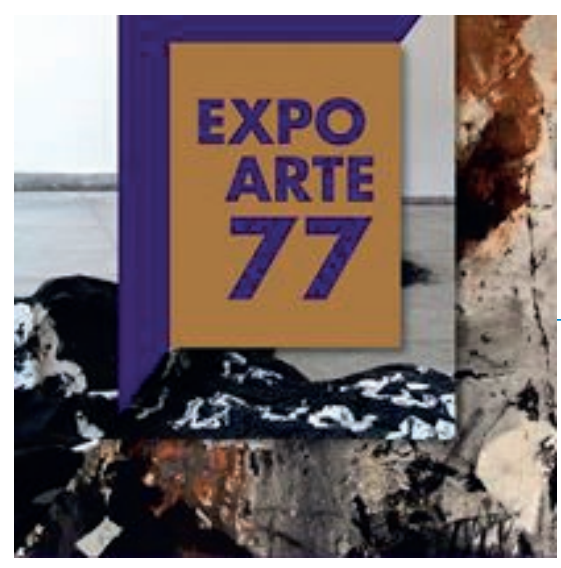

EXPOSICIÓN ANUAL DISEÑO GRÁFICO. Facultad de Arte y Diseño Gráfico de la Pontificia Universidad Católica del Perú. Entre el 9 y 30 de junio se presentaron en la Galería de Artes Visuales del Centro Cultural Ccori Wasi, los proyectos realizados por los estudiantes de la carrera de Diseño Gráfico, con los que buscaban hacer hincapié sobre la importancia del diseño y su presencia en todas las actividades humanas, a través de elementos semióticos. "Porque la inmersión del diseño en la cultura supera los parámetros circunstanciales de la producción y promoción de productos de diseño, para convertirse en un generador de ideas; porque desarrolla valores de pensamiento y opinión con respecto a la cultura y la sociedad en que interviene". 

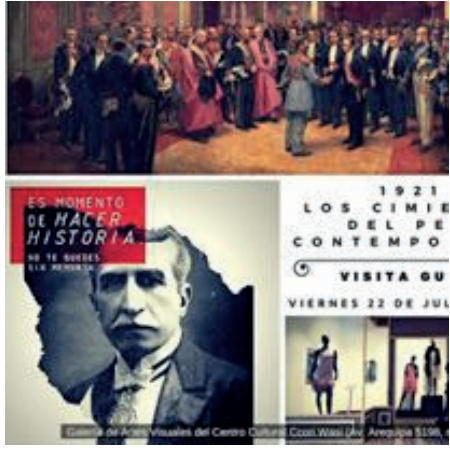

1921, LOS CIMIENTOS DEL PERÚ CONTEMPORÁNEO. Propuesta expositiva coordinada por el Arq. Leopoldo Lituma, a propósito de la celebración de Fiestas Patrias y la preparación para el Bicentenario de nuestra Independencia. A través del uso de diversos recursos museográficos mostró personajes y momentos de nuestra historia republicana. La exposición se presentó del 7 al 31 de julio, en la Galería de Artes Visuales del Centro Cultural Ccori Wasi.

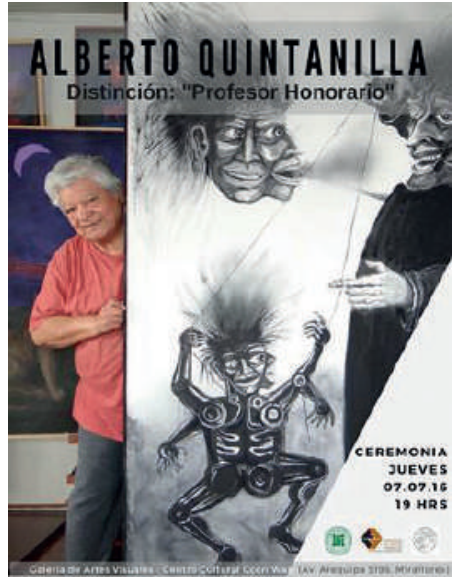

DISTINCIÓN AL MAESTRO ALBERTO QUINTANILLA. En el marco de las celebraciones por el $47^{\circ}$ aniversario de la fundación de la Universidad Ricardo Palma, el maestro Alberto Quintanilla fue distinguido como "Profesor Honorario", dada su trayectoria y reconocimiento a nivel mundial por la temática de su pintura que, a pesar de las modas y los cambios de estilo en el mundo, es figurativa y fiel reflejo de la cultura de los pueblos andinos, en especial de la histórica ciudad de Cusco.

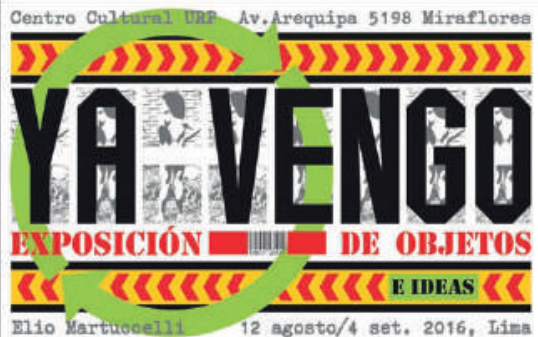

YA VENGO. Propuesta artística a cargo del Arq. Elio Martuccelli, en la que nos llevó, por medio del uso de diversas técnicas, a recorrer sus últimos doce años de trabajo artístico, en el que resalta un "arte político-erótico-místico" a través de intervenciones en espacios públicos, instalaciones y escenografías, las que se caracterizan no solo por los colores vivos sino también por el sarcasmo, humor, critica y denuncia sobre temas políticos y sociales, así también como el personal. La exposición tuvo lugar desde el 12 de agosto hasta el 04 de setiembre. 


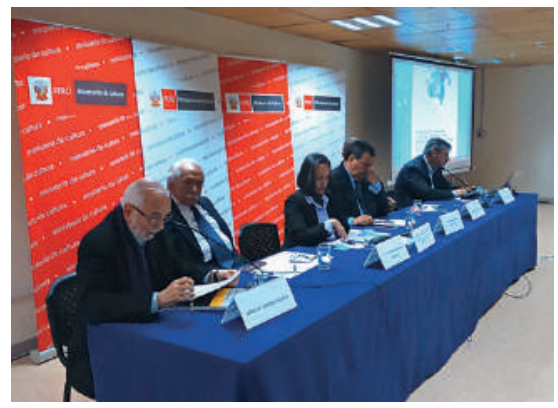

El 5 de octubre, el Dr. Alfonso Castrillón, Director del Instituto de Investigaciones Museológicas y Artísticas, participó en la Mesa Redonda: LA IDEA DE UN MUSEO NACIONAL dentro del conversatorio sobre el Museo Nacional de Arqueología (MUNA), cuyo evento se llevó a cabo en las instalaciones del Ministerio de Cultura. De izquierda a derecha: Dr. Alfonso Castrillón Vizcarra, Dr. Luis Guillermo Lumbreras, Lic. Ana Castillo Aransaenz -Viceministra de Patrimonio Cultural e Industrias Culturales-, Dr. Jorge Nieto Montesinos -Ministro de Cultura-, Mg. Alfredo Narváez y el Dr. Luis Jaime Castillo.

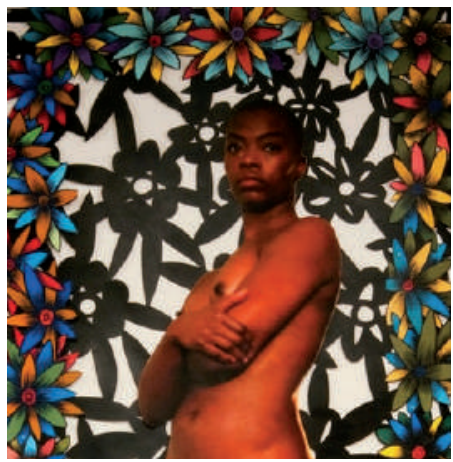

PAISAJES. Del artista venezolano Henry Bermúdez, "La muestra está inspirada en la mitología, la política y la estética, en donde el elemento técnico fundamental es el papel, con el que traduce en obras de arte mitos de la cultura latinoamericana, entremezclada con estereotipos de la cultura universal, sobre todo la judeo-cristiana, que se fusionan al punto de crear obras sin referentes específicos". La exposición se presentó del 7 al 31 de octubre en la Galería de Artes Visuales del Centro Cultural Ccori Wasi.

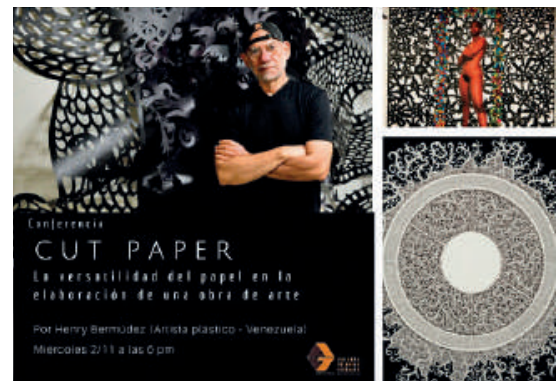

CUT PAPER. La versatilidad del papel en la elaboración de una obra de arte. En el marco de la exposición "PAISAJES", el 02 de octubre, Henry Bermúdez, nos brindó una charla magistral en la que hizo un recuento de su experiencia como artista y el desarrollo de su técnica. El diálogo entre los asistentes y el artista generó un agradable e interesante ambiente, debatiendo sobre el papel actual de los artistas latinoamericanos y su identificación con su cultura. La mesa contó con la participación del artista Gerardo Chávez y Manuel Munive, curador de la muestra. 


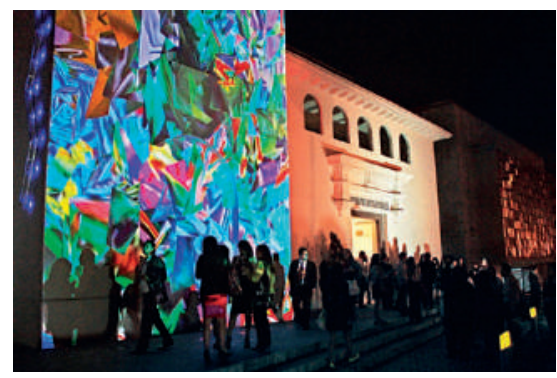

\section{Er E Desafío de la Realidad}

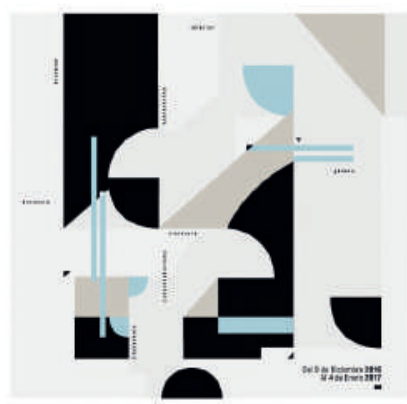

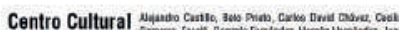

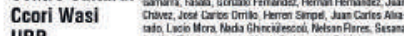
URP

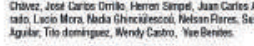

LIMA DESIGN WEEK, dirigido por Teresa Edwards "es un festival donde se expresa y muestra toda la riqueza del diseño, el arte y la cultura de cada participante y del país. Es una fuente de estímulo para que se sumen más diseñadores a expresar sus ideas y desarrollar su creatividad muchas veces oculta o no conocidas". Su cuarta edición se desarrolló del 8 al 20 de noviembre en la Galería de Artes del Centro Cultural Ccori Wasi y reunió a lo más destacado del diseño multidisciplinario, el arte y la cultura.
La Galería de Artes Visuales, en su última exposición del año ARTISTAS VISUALES TRUJILLANOS: EL DESAFíO DE LA REALIDAD, presentó a 18 artistas de la ciudad de Trujillo, rostros nuevos en las artes visuales que se inscriben dentro del sentido del arte como globalización. Con producciones de Carlos David Chávez, Juan Chávez, Juan Carlos Alvarado Salvatierra, Gonzalo Fernández, Wendy Castro, Susana Aguilar Yauri, José Carlos Orrillo, Lucio Mora, Hernán Hernández, Fasalá, Nelson Flores, Beto Prieto, Cecilia Gamarra, Nadia Ghinciülescoú, Yue Benites, Herren Simpel, Alejandro Castillo y Tito Domínguez. Bajo la coordinación de Alfredo Alegría Alegría, crítico de arte. La exposición fue inaugurada el 9 de diciembre y permanecerá en las salas de la Galería de Artes Visuales hasta el 4 de enero de 2017.

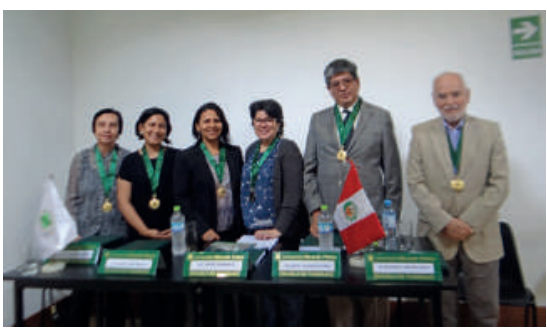

El 21 de diciembre tuvo lugar la disertación de la tesis "Propuesta de Plan Museológico para la Casa Museo Ricardo Palma" de la Bach. María Eugenia Yllia Miranda, egresada de la Maestría en Museología y Gestión Cultural. En la Foto de Izq. A Derech. Mg. Elena Cano Correa, Mg. Anita Tavera Tavera, Mg. María Eugenía Yllia Miranda, Dra. Rocio Trinidad Zapata, Dr. Alberto Martorell Carreño, Dr. Alfonso Castrillón Vizcarra. 